\title{
STATİK YÜKLÜ RADYAL KAYMALI YATAKLARDA HİDRODİNAMİK YAĞLAMANIN ANALİZI
}

\author{
Güler ÖNCÜ1* ${ }^{*}$ Ertuğrul DURAK²
}

\begin{abstract}
${ }^{1}$ Isparta Uygulamalı Bilimler Üniversitesi, Teknik Bilimler Meslek Yüksekokulu, Isparta, Türkiye 2 Süleyman Demirel Üniversitesi, Mühendislik Fakültesi, Makine Mühendisliği Bölümü, Isparta, Türkiye
\end{abstract}

\begin{tabular}{ll}
\hline Anahtar Kelimeler & Öz \\
\hline Radyal Kaymalı Yatak, & Hidrodinamik yağlamalı kaymalı yataklarda basınç dağılımı, sürtünme katsayısı, yağ \\
Reynolds Denklemi, & film kalınlığı, yağ debisi, vb. gibi değerler yatak tasarımı ve optimum enerji \\
Sonlu Farklar Yöntemi, & verimliliği açısından büyük öneme sahip tasarım kriterleridir. Bu çalışmada basıç \\
Hidrodinamik Yağlama, & dağılımını ifade eden Reynolds Yağlama Diferansiyel denklemi sonlu farklar metodu \\
Triboloji. & ile çözülerek her bir basınç noktası için iteratif çözüm yapılmıştır. Çalışmada \\
& kurgulanan algoritma ile muylu hızının değişimi ile basınç değeri, yağlayıcı katman \\
& kalınlığı, sürtünme katsayısı ve yatak kapasitesi belirlemek mümkündür. Hazırlanan \\
& MATLAB programı ile elde edilen sonuçlar benzer çalışmalarla kıyaslanmıştır. \\
\hline
\end{tabular}

\section{ANALYSIS OF HYDRODYNAMIC LUBRICATION IN STATIC LOADED JOURNAL BEARING}

\begin{tabular}{l} 
Keywords \\
\hline Journal Bearing, \\
Reynolds Equation, \\
Finite Difference Method, \\
Hydrodynamic Lubrication, \\
Tribology.
\end{tabular}

Alıntı / Cite

Öncü, G., Durak, E., (2021). Statik Yüklü Radyal Kaymalı Yataklarda Hidrodinamik Yağlamanın Analizi, Mühendislik Bilimleri ve Tasarım Dergisi, 9(1), 167-175.

Yazar Kimliği / Author ID (ORCID Number)

G. Öncü, 0000-0002-3139-4554

E. Durak, 0000-0001-6957-3796

\begin{abstract}
distribution, friction coefficient, oil film thickness, oil flow rate, etc. are important design criteria in terms of bearing design and optimum energy efficiency in hydrodynamic lubricated journal bearings. In this study, pressure distribution, in every pressure point, is determined while using finite difference method with Reynolds Lubrication Differential Equation iteratively. With the algorithm designed in the study, it is possible to determine the pressure value, lubricant layer thickness, friction coefficient and bearing capacity by changing the journal speed. The results obtained with the MATLAB program prepared were compared with similar studies.
\end{abstract}

\section{Giriş (Introduction)}

Makine elemanlarının önemli bir alanını oluşturan yatakların temel amacı, hareketin sürekliliğini en az kayıp ile sağlayarak millerin desteklenmesidir. Yataklar yapılarına göre kaymalı, yuvarlanma elemanlı ve hassas cihaz yatakları; kaymalı yataklar ise yük taşıma durumlarına göre; eksenel, radyal ve eksenel-radyal kaymalı yataklar olarak incelenebilmektedir. Kaymalı yataklarda, mil ve yatak arasındaki yüzeyler bir akışkan film ile birbirinden tamamen ayrıldığı için tam sıvı sürtünme ile birlikte, herhangi bir dış etki olmaksızın yatağa gelen kuvvetin dengelenmesi gerekmektedir. Bu nedenle hidrodinamik ve hidrostatik olmak üzere iki yağlamadan bahsetmek mümkündür. Hidrodinamik yağlamada; yüzeyler arasındaki boşluğun şekline ve yüzeylerin hızına bağlı, iki yüzeyi birbirinden tamamen ayıran yeterli basınca sahip bir yağ tabakası oluşturulabilmektedir.

Buna karşılık hidrostatik yağlamada, dış kuvveti dengelemek için yağ tabakasındaki basınç, bir pompa aracılığı ile oluşturulmaktadır (Kurban, 1990). Hidrodinamik yağlamanın sayısal analizi, yatak özelliklerinin tahmin

\footnotetext{
* ilgili yazar / Corresponding author: guleroncu@isparta.edu.tr, +90-246-214-6930
} 
edilmesinde ve mühendislik için gereken problem çözümlerinde etkili olmaktadır (Nuruzzaman vd. 2010). Eksenel ve radyal kaymalı yataklarda, hidrodinamik yağ filmi içerisindeki basınç dağılımı, yağ katkı maddelerinin yatak performansına etkisi, mikro kanallı yataklarda sürtünme davranışı gibi yağlama ve yataklarla ilgili birçok deneysel ve teorik çalışmalar mevcuttur (Sun ve Changlin, 2004; Woloszynski vd., 2015; Singh vd., 2020; Salman ve Durak, 2011; Durak 2003; Adatepe ve Bıylklığlu 2009 ). Kaymalı yatakların bilimsel araștırması, Tower'ın 1883'de yayınladığı deneysel çalışması ve aynı yıl Petroff'un yataktaki sürtünmeyi viskoz sürtünmeye bağlayan hipotezi ile bașlayıp 1886'da Reynolds'un hidrodinamik yağlama genel denklemini vermesiyle genişleyerek devam etmiștir (Kurban, 1990). Hashimoto(1997) tarafindan yapılan çalışmada, kaymalı yataklarda yüzey pürüzlülügü ve türbülansın etkileri göz önüne alınarak Reynolds denklemi modifiye edilerek çözümler sunulmuştur. Kaymalı yataklar hakkındaki pek çok çalışma bulunmakta ve çalışmalar hala devam etmektedir. Myung vd.(2000), motor yataklarındaki çevresel yağ kanallarının minimum yağ kalınlı̆̆ı üzerindeki etkilerini araştırarak Reynolds diferansiyel denkleminin, sonsuz uzunluktaki yatak boyu modeline göre akışkan film basıncı hesaplanmış ve çevresel kanallı ile çevresel kanalsız yataklar için sonuçlarını karşılaştırmıştır.

Wang vd. (2016) yağlayıcı olarak su kullanan radyal kaymalı yataklarda basınç dağılımını sonlu elemanlar yöntemi kullanarak elde etmişlerdir. Çalışmada farklı mil dönüş hızları ve malzeme Elastisite Modülü ve Poisson oranının yük taşıma kapasitesi ve elastik deformasyon üzerindeki etkileri incelenmiștir. Santos vd.(2012) tarafından yapılan çalışmada, integral dönüşüm teknikleri ile radyal kaymalı yataklarda hidrodinamik yağlama analizi yapılmıştır. Syfris ve Chasalevris (2012) sonlu uzunluktaki bir kaymalı yataktaki yağlayıcının basınç dağılımı için Reynolds denklemini analitik olarak çözüp, basınç profil diyagramlarını yaklaşık analitik ve sayısal çözümlerle karşılaştırmışlardır. Mane ve Soni (2013) tarafından Reynolds denklemi sonsuz kısa ve sonsuz uzun mil yatağı için teorik olarak çözülmüş ve simülasyon sonuçlarını elde etmek için Comsol yazılımı kullanılarak analitik sonuçlar arasında karşılaştırma yapılmıştır. Liu vd. (2010) karmaşık bir rotor yatak sisteminin elasto-hidrodinamik yağlamasını analiz etmek için Navier-Stokes denklemine ve bir akışkan-yapı etkileşimi tekniğine dayanan hesaplamalı akışkanlar dinamiğini kullanarak bu tekniklerinin, hidrodinamik ve elastohidrodinamik yağlamanın araştırılması için yararlı bir araç olduğu göstermişlerdir. Gao vd. (2014), su ile kaymalı yatağın hidrodinamik yağlama altında sayısal analizini yaparak Ansys-Fluent programı ile, Şimşek (2014), Kissoft programı ile teorik sonuçları deneysel sonuçlarla karşılaştırmışlardır. Tobias (2016), kaymalı yataklar için, Comsol yazılımını kullanarak, daha önceki çalışmalardan elde edilen verileri karşılaştırarak, hem statik hem de dinamik analizlerle yatak parametrelerini hesaplamıştır.

Bu çalışmada; Reynolds denklemi sonlu farklar yöntemi kullanılarak, basınç alanını ağ yapılarına bölerek her bir basınç noktası için iteratif bir çözüm yapılarak algoritma oluşturulmuştur. Matlab'de yazılan program ile elde edilen basınç değerleri benzer çalışmalarla karşılaştırılmıştır. Literatürden seçilen örnek yatak parametreleri ile elde edilen sonuçlar irdelenmiştir.

\section{Materyal ve Yöntem (Material and Method)}

\subsection{Hidrodinamik Yağlama Teorisi (Hydrodynamic Lubrication Theory)}

Hidrodinamik yağlama, yüzeyler arasındaki boşluğun şekline ve izafi hızına bağlı olarak yüzeylerin birbirinden tamamen ayrılması için yeterli basınca sahip bir yağ tabakası oluşturan yağlama sistemidir. Hidrodinamik yağlama teorisinin amacı; yağ filmi içinde hangi koşullarda yatakta (Şekil 1) basıncın oluştuğunu ve bu basıncın nasıl değiştiğini belirlemektir. Daha sonra buna bağlı olarak yatağın yük taşıma kapasitesi başta olmak üzere gerekli yağ miktarını, minimum yağ film kalınlığını, sıcaklığı, sürtünme katsayısını ve gerekli yatak temel boyutlarını hesaplayabilmek için ihtiyaç duyulan eșitlikleri belirlemektir. Hidrodinamik yağlama denklemi, Reynolds yağlama diferansiyel denklemi olarak bilinmektedir. Bu denklemin esası Navier-Stokes hareket denklemlerine dayanıp ilave olarak da süreklilik denklemi, akışkanların hareketi ve yoğunluğu ile ilgili denklemleri de dikkate almaktadır. Reynolds diferansiyel denklemi, başlangıç koşulları belirlenerek ve bir takım ön kabuller ile çözülmektedir. (Budynas ve Nisbett, 2006).

Reynolds'un temel yağlama diferansiyel denklemi başlangıç olarak şu şekilde verilir (Frene vd. 1990);

$$
\frac{\partial}{\partial x}\left(h^{3} \frac{\partial P}{\partial x}\right)+\frac{\partial}{\partial x}\left(h^{3} \frac{\partial P}{\partial z}\right)=6 \eta U \frac{\partial h}{\partial x}
$$

Uygulanan eksantriklik için; Reynolds denklemi,

$$
\frac{\partial^{2} P}{\partial x^{2}}+\frac{\partial^{2} P}{\partial z^{2}}+\frac{3}{h} \frac{\partial h}{\partial x} \frac{\partial P}{\partial x}+\frac{3}{h} \frac{\partial h}{\partial z} \frac{\partial P}{\partial z}=\frac{6 \eta U}{h^{3}} \frac{\partial h}{\partial x}
$$




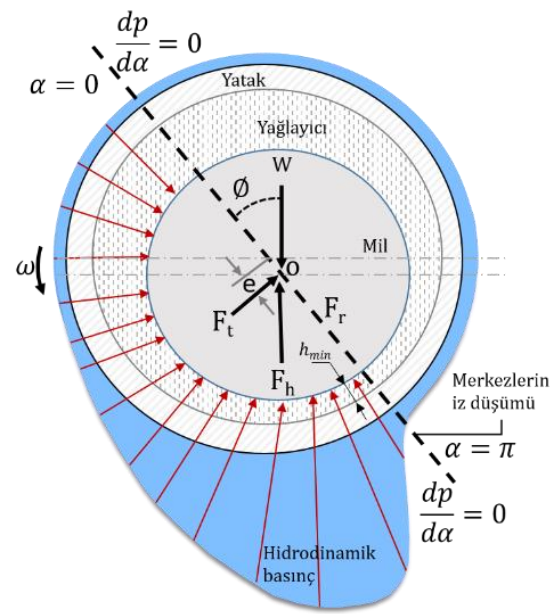

Şekil 1. Hidrodinamik kaymalı yataklarda basınç dağılımı

(Pressure distribution in hydrodynamic journal bearings) (Razavykia vd. 2019)

\section{2 Sonlu Farklar Metodu (Finite Differences Method)}

Tribolojik çalışmalar sırasında fiziksel değerler genellikle fizik yasalarını tanımlayan diferansiyel denklemler olarak verilir ve bu denklemler analitik olarak çözülebilir. Ancak birçoğunun çözülmesi (doğrusal olmayan kısmi diferansiyel denklemler ) zor ve karmaşık olabilir. Gerekli çözümü yaklaşık olarak veren temel hesaplama yöntemleri; sonlu fark, sonlu elemanlar ve sonlu hacim yöntemleridir. Bu yöntemler, dikkate alınan sürekli alanın sınırlı sayıda alt bölüme bölünmesine (ağ oluşturma) ve ardından bu alt bölümlerde yaklaşı çözümlerin bulunması esasına dayanır (Grabon ve Smykla 2012). Pek çok pratik mühendislik uygulaması için, yağlama boyunca viskozitenin sabit olduğu varsayılır. Frene (1998)'e uygun olarak yapılan bu çalışmada da sabit sıcaklıkta sabit vizkosite değeri alınmıștır. Buna göre akışkan film basıncı, Matlab ile hazırlanan, program yardımıyla hesaplanmıştır. Hesaplamada kullanılan örnek ağ yapısı Şekil 2'de verilmiştir.

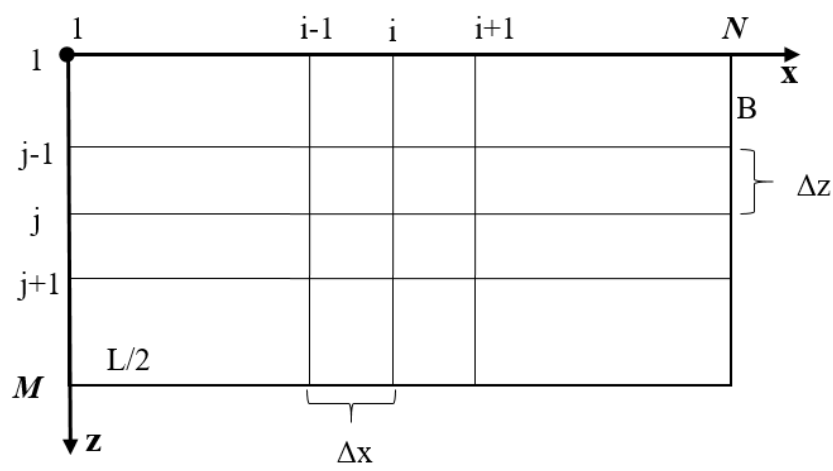

Şekil 2. Simetri şartlarında örnek ağ yapısı(grid structure)

Yağlayıcı film basınç alanı p (x, z) hesaplaması, sonlu farklar metodu nümerik çözümü;

$$
\begin{aligned}
& \frac{\partial P}{\partial x}(i, j) \approx \frac{p(i+1, j)-p(i-1, j)}{2 \Delta x} \\
& \frac{\partial P}{\partial z}(i, j) \approx \frac{p(i, j+1)-p(i, j-1)}{2 \Delta z} \\
& \frac{\partial^{2} P}{\partial x^{2}}(i, j) \approx \frac{p(i+1, j)-2 p(i, j)+p(i-1, j)}{\Delta x^{2}} \\
& \frac{\partial^{2} P}{\partial z^{2}}(i, j) \approx \frac{p(i, j+1)-2 p(i, j)+p(i, j-1)}{\Delta z^{2}}
\end{aligned}
$$


Sonlu farklar metodunun Reynolds denklemine uygulanmasından sonra oluşan denklem sistemi;

$$
\begin{aligned}
& -p(i, j)\left(\frac{2}{\Delta x^{2}}+\frac{2}{\Delta z^{2}}\right)+p(i+1, j)\left(\frac{1}{\Delta x^{2}}+\frac{1}{2 \Delta x}+\frac{3}{h} \frac{\partial h}{\partial x}\right)+p(i-1, j)\left(\frac{1}{\Delta x^{2}}-\frac{1}{2 \Delta x}+\frac{3}{h} \frac{\partial h}{\partial x}\right)+p(i, J+1)\left(\frac{1}{\Delta z^{2}}+\right. \\
& \left.\frac{1}{2 \Delta x}+\frac{3}{h} \frac{\partial h}{\partial x}\right)+p(i, j-1)\left(\frac{1}{\Delta z^{2}}+\frac{1}{2 \Delta z}+\frac{3}{h} \frac{\partial h}{\partial z}\right)=\frac{6 \mu U}{h^{3}} \frac{\partial h}{\partial x}
\end{aligned}
$$

olarak elde edilir, bu denklem sisteminin çözümde kullanılan sınır şartları ise;

$$
\begin{aligned}
& x=0 \quad i=1 \quad j \in[1, M-1] \quad p(1, j)=p s \\
& x=B \quad i=N \quad j \in[1, M-1] \quad p(N, j)=p s
\end{aligned}
$$

şeklinde belirlenerek çözüm değerlerinin bulunması ile yük;

$$
\mathrm{W}=(\mathrm{Wr} 2+\mathrm{Wt} 2) 1 / 2
$$

sürtünme katsayısl;

$$
\mu=\frac{C a}{R \cdot W}
$$

ile hesaplanabilir. Çözümde kullanılan değişkenlere ait tanımlamalar şu şekildedir;

$$
\begin{aligned}
& \text { p:basınçৎPa], } \\
& \text { D:Yatak çapı } \\
& \text { B: Yatak Genişliği } \\
& \text { R: D/2 Yatağın Yarıçapı } \\
& \text { L:Yatak Uzunluğu } \\
& \text { h:Yağ film kalınlığı } \\
& \text { E:Eksantrisite oranı } \\
& \text { W:Yük taşıma Kabiliyeti }
\end{aligned}
$$

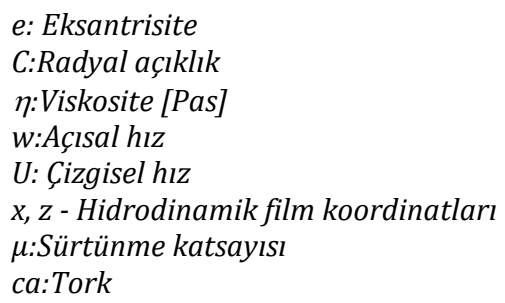

Bilgisayar programı hazırlanırken özellikle Reynolds Diferansiyel denkleminin nümerik ve analitik çözüm algoritmaları incelenmiștir. Hazırlanan Matlab paket programı ile algoritmalar yeniden analiz edilerek farklı altı araştırma tarafından kullanılan program ve deney sonuçları kıyaslanarak benzerlik ve farklılıklar analiz edilmiştir. Temel algoritmaya ait akış şeması Şekil 3'de verilmiştir.

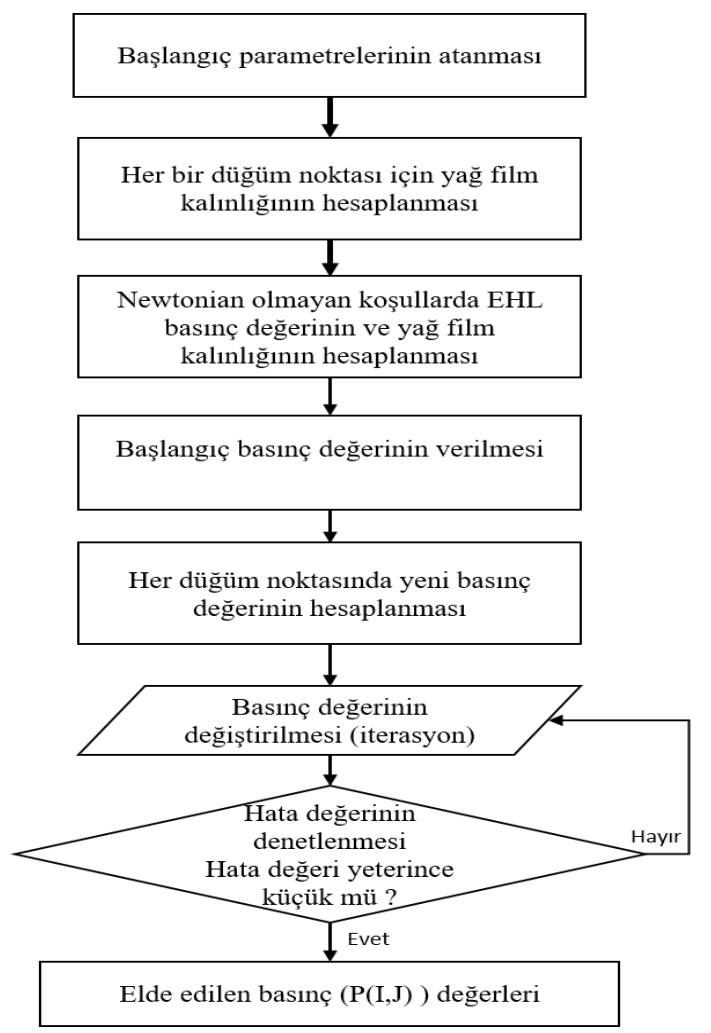

Şekil 3. Bilgisayar programı akış diyagramı (Flowchart of the implemented solution) 


\section{Araştırma Bulguları ve Tartışma (Results and Discussion)}

\subsection{Hazırlanan Programın Doğrulanması ve Diğer Çalışmalarla Karşılaştırılması (Test and Verification by Reference Studies)}

Yükün dikey bir eksen boyunca uygulandığı farklı araştırmacılar tarafından incelenen kaymalı yatak için geometrik parametreler ve çalışma koşulları (Tablo 1 ve 2) verilmiş olup deney sonuçları hazırlanan programla kıyaslanmıştır (Şekil 4 ve 5).
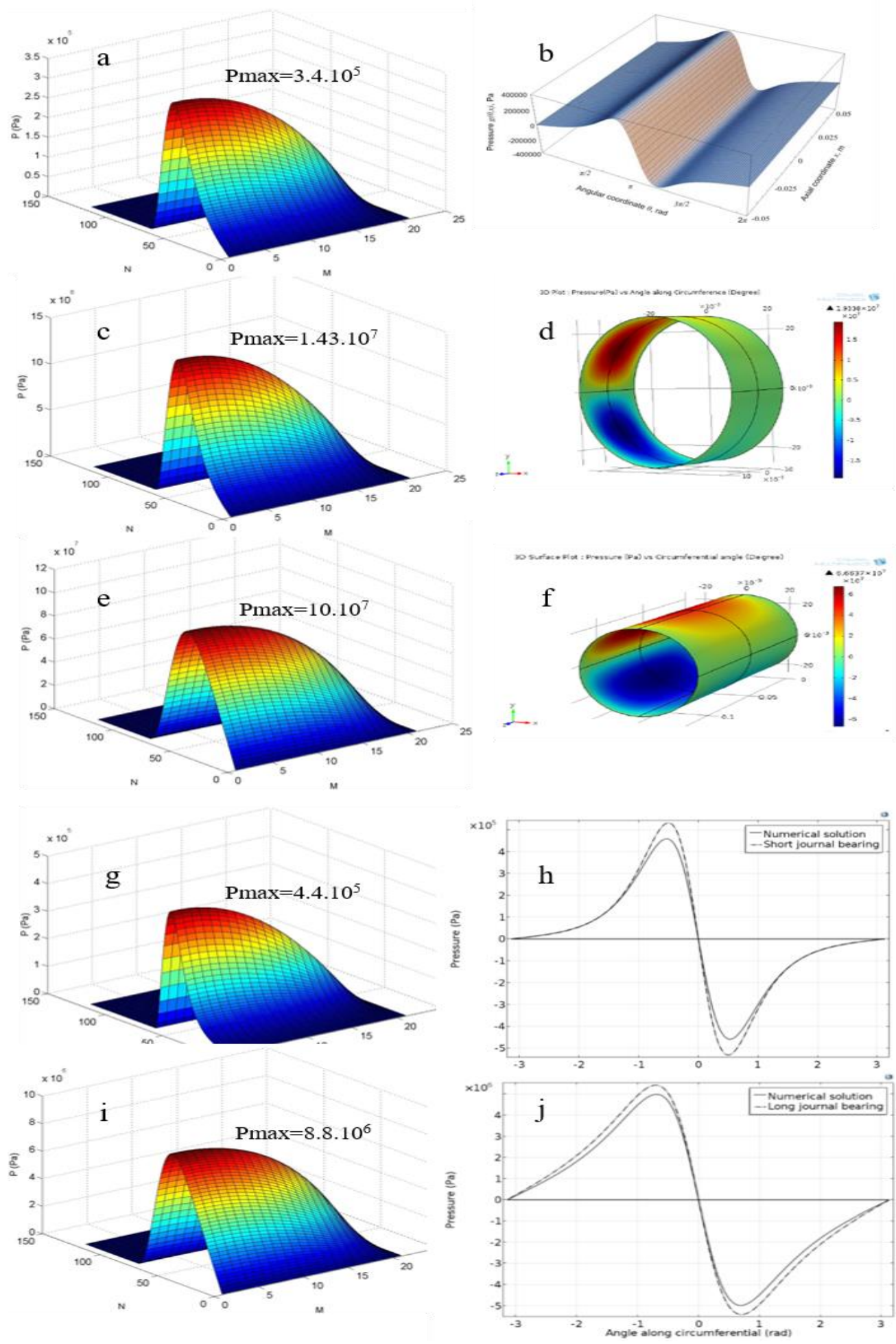

Şekil 4. Bu çalışmada hesaplanan basınç değerleri (a, c, e, g, i ) ve Tablo 1'de verilen referans çalışmalara ait basınç değerleri $(b, d, f, h, j)$. (Pressure values in this study $(a, c, e, g, i)$ and reference study values in Table $1(b, d, f, h, i)$ ) 
Tablo 1. Karşılaștırmada kullanılan yatak parametreleri (Reference journal parameters used at comparison)

\begin{tabular}{|c|c|c|c|c|c|}
\hline Parametre & $\begin{array}{c}\text { Syfris ve } \\
\text { Chasalevris } \\
(2012) \\
\mathrm{b}^{*}\end{array}$ & $\begin{array}{c}\text { Mane ve Soni } \\
(2013) \\
\text { (kısa yatak) } \\
\mathrm{d}^{*}\end{array}$ & $\begin{array}{c}\text { Mane ve Soni } \\
(2013) \\
\text { (uzun yatak) } \\
\mathrm{f}^{*}\end{array}$ & $\begin{array}{c}\text { Tobias } \\
(2016) \\
\text { (kısa yatak) } \\
\mathrm{h}^{*}\end{array}$ & $\begin{array}{c}\text { Tobias } \\
(2016) \\
\text { (uzun yatak) } \\
\mathrm{j}^{*}\end{array}$ \\
\hline Yarıçap (mm) & 50 & 25 & 25 & 15 & 15 \\
\hline Uzunluk (mm) & 100 & 25 & 125 & 7.5 & 75 \\
\hline Açıklık (mm) & 0.5 & 0.025 & 0.025 & 0.03 & 0.03 \\
\hline Eksantrisite oranı & 0.7 & 0.5 & 0.5 & 0.6 & 0.6 \\
\hline Mil hızı [d/d] & 955 & 1000 & 1000 & 2000 & 2000 \\
\hline Viskozite [Pa s] & 0.05 & 0.19 & 0.19 & 0.02 & 0.02 \\
\hline
\end{tabular}

Syfris ve Chasalevris(2012) tarafından yapılan çalıșmada, basınç dağılım eğrisi bu çalıșmada hesaplanan basınç değeri ile uyumludur. Mane ve Soni (2013) ve Tobias (2016) tarafindan yapılan çözümler Comsol ortamında yapılmıştır. Mevcut çalışma ile karşılaş̧ırıldı̆̆ında, kısa yatak için elde edilen pmax değerleri uyumlu iken, uzun yatak için hesaplanan değerler, referans çalışmaya göre, daha yüksek hesaplanmıştır (Şekil 4).

Gao vd. (2014) ve Wang vd. (2016) tarafından, Pmax hesabı için kullanılan, farklı mil hızı ve viskozite değerleri ile farklı eksantrisite oranlarına göre de (Tablo 2) denklem çözümleri yapılmıştır. Elde edilen basınç değerleri, referans çalışmalardan yüksek olmakla birlikte, değişimleri birbirine paraleldir.

Tablo 2. Farklı eksantrisite oranları $(0.4,0.5,0.6,0.7,0.8)$ için yatak parametreleri (Journal parameters at different eccentricity ratios $(0.4,0.5,0.6,0.7,0.8)$ )

\begin{tabular}{|c|c|c|c|}
\hline Parametreler & Gao (2014) & Wang (2016) Su & Wang (2016) Yağ \\
\hline Yarıçap (mm) & 40 & 40 & 40 \\
\hline Uzunluk (mm) & 80 & 80 & 80 \\
\hline Açıklık (mm) & 0.04 & 0.04 & 0.04 \\
\hline Mil hızı [d/d] & 1500 & 2000 & 2000 \\
\hline Yağ viskozitesi [Pa s] & 0.001 & 0.001 & 0,02 \\
\hline
\end{tabular}

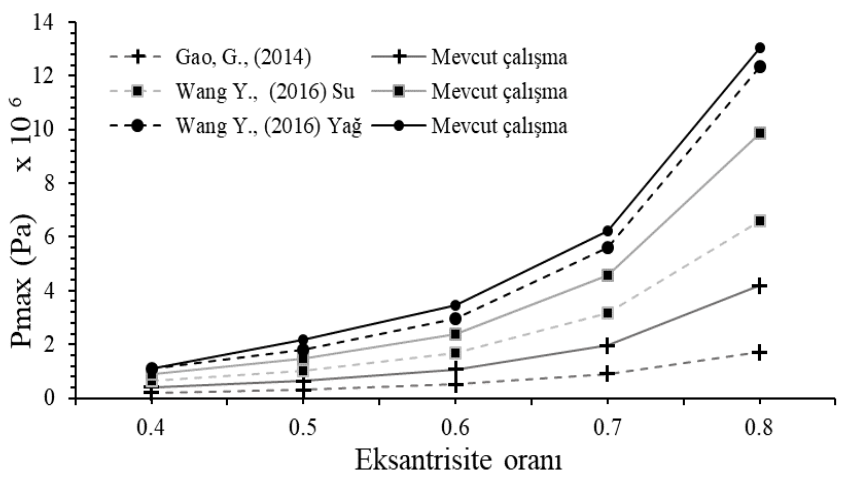

Şekil 5. Farklı eksantrisite oranları $(0.4,0.5,0.6,0.7,0.8)$ için Pmax basınç değerlerinin karşılaştırılması

(Pressure values at different eccentricity ratios $(0.4,0.5,0.6,0.7,0.8)$ )

Ayrıca hem deneysel hem teorik çalışmanın birlikte yapıldığı alüminyum alaşımlı AA7075 malzemeli silindirik ve tek parça halinde $3 \mathrm{~mm}$ yağlama deliğine sahip bir yatağa ait veriler Tablo 3' de verilmiştir (Şimşek 2014). Statik yük altında radyal kaymalı yatakların sürtünme davranıșının teorik olarak belirlenmesini içeren DIN 31652'e göre de hesaplamalar yapılmıştır. Elde edilen teorik minimum yağ film kalınlığı Şekil 6' da, sürtünme katsayısı da Şekil 7' de verilmiştir. Yağ film kalınlığının artmasından, mil merkezinin yatak merkezine yaklaștığı ve mil yüzeyinin yatak yüzeyinden uzaklaştığı anlaşılmaktadır. Ayrıca bu değişim de eksantrisite oranının azalmasına sebep olmaktadır. Düşük hızlarda sürtünme katsayısının küçük değerlerde olması Reynolds denkleminin sadece akışkan molekülleri arasındaki viskoz sürtünme esasına dayandırılmasından kaynaklanmaktadır.

Diğer yandan yağlama literatüründen (Durak 2019; Adatepe vd. 2012; Temiz 2014; Soydan ve Ulukan 2013; Koç 2008) Stribeck eğrisinde, düşük hızlarda, sürtünme katsayıları (sınır yağlama bölgesinde) çok daha büyük değerlerdedir. Çünkü bu bölgede sürtünme katsayısı yatak - mil yüzey pürüzlerinin temasında oluşan mekanik 
sürtünme ile yağ molekülleri arasındaki viskoz sürtünme katsayılarının toplamından oluşmaktadır. Sıvı yağlama bölgesinde ise artan hız ile sürtünme katsayısı artması kayma gerilmesi sonucundadır. Ayrıca yük taşıma kabiliyeti ve yatak yükünün mil hızı ile değişimi de Şekil 8' de verilmektedir. Bu grafikte görüldüğü gibi düşük hızlarda yağ filminin içerisindeki yağ basıncının oluşturduğu yük tașıma kabiliyeti daha yüksek değerde olup hızın artması ile yatağa uygulanan yüke göre daha fazla düșüş eğilimi göstermektedir. Bu düşüşe, hızın artması ile eksantrisite oranında oluşan azalmanın sebep olduğu açıktır. Çünkü mil merkezi yatak merkezine doğru hareket ettikçe yağ film basınç dağılımının azaldığı bunun da yük taşıma kabiliyetini azalttığı anlamına gelmektedir. Ancak yine de tüm çalışma şartlarında yük taşıma kabiliyeti yatağa uygulanan yükten daha büyüktür.

Tablo 3. Bu çalışmada kullanılan Şimşek (2014)' e ait yatak parametreleri (Bearing parameters used in this study)

\begin{tabular}{|l|l|}
\hline Parametre & Parametre değeri \\
\hline Mil çapı dmax[mm] & 41.935 \\
\hline Mil çapı dmin[mm] & 41.9348 \\
\hline zYatak iç çapı Dmax[mm] & 41.9756 \\
\hline Yatak iç çapı Dmin[mm] & 41.975 \\
\hline Yatak genişliği & $25 \mathrm{~mm}$ \\
\hline Mil hızı [d/d] & $5,10,50,100,250,500,750,1000$ \\
\hline Yağ sıcaklığı $\left[{ }^{\circ} \mathrm{C}\right]$ & 40 \\
\hline Mil yüzey pürüzlülüğü Ra[ $\mu \mathrm{mm}]$ & 0.126 \\
\hline Yağ viskozitesi $[\mathrm{Pa}$ s] & 0.156 \\
\hline Yük [N] & $150,250,500$ \\
\hline Ortam sıcaklığı $\left[{ }^{\circ} \mathrm{C}\right]$ & 25 \\
\hline
\end{tabular}

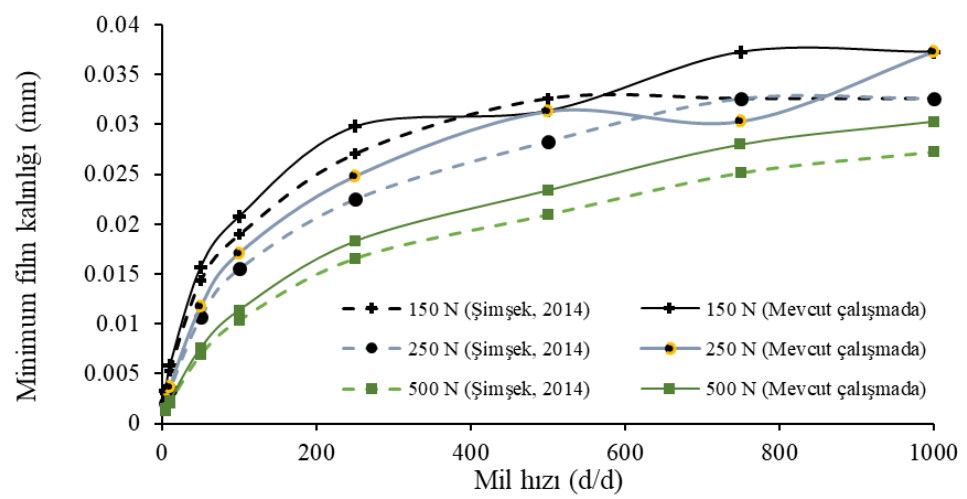

Şekil 6. Mevcut çalıșmada hesaplanan minimum yağ film kalınlığı - mil hızı değișiminin Şimşek (2014) ile karşılaştırmalı grafiği (Lubricant film thickness vs journal speed comparison with Şimşek(2014))

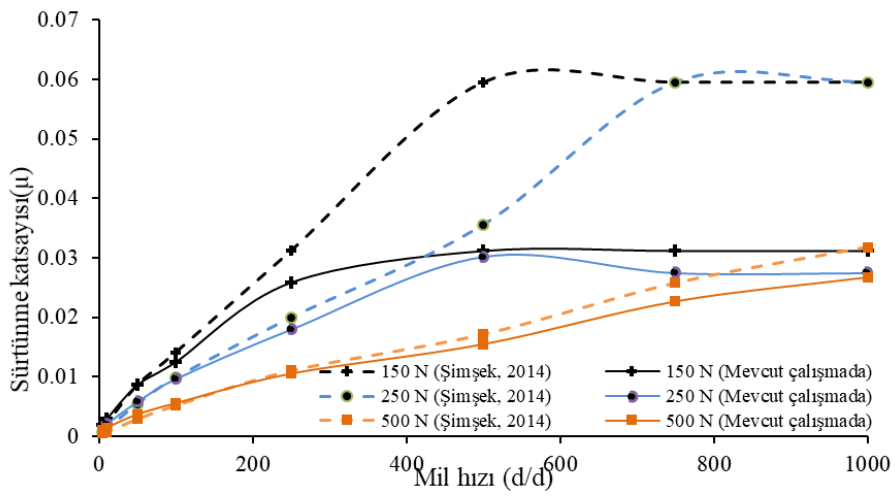

Şekil 7. Mevcut çalışmada hesaplanan minimum sürtünme katsayısı - mil hızı değișiminin Şimşek (2014) ile karşılaştırmalı grafiği (Friction coefficient vs shaft speed comparison with Şimşek(2014)) 


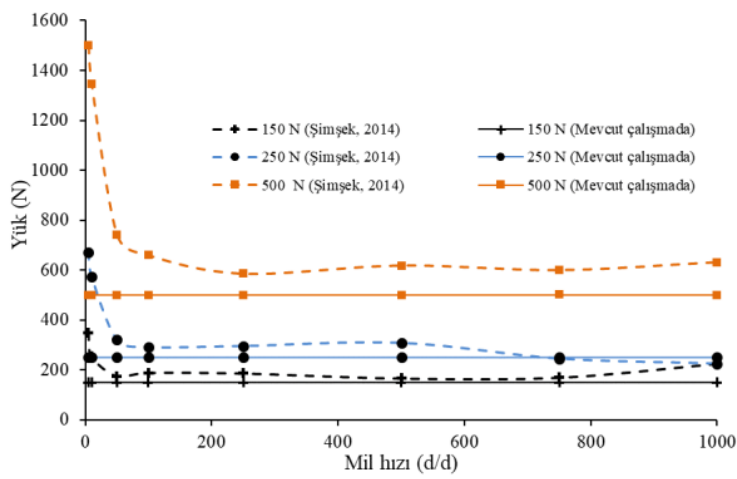

Şekil 8. Mevcut çalıșma ile hesaplanan yük taşıma kabiliyeti ve yatak yükünün mil hızı ile değișiminin Şimşek (2014) ile karşılaştırmalı grafiği (Comparison to change of the bearing capacity and load vs shaft speed with Şimşek(2014))

\section{Sonuçlar (Conclusions)}

Tribolojik problemlerin modellenmesi ve çözümü için bilgisayar teknolojilerinin kullanımı sayesinde hızlı sayısal hesaplamalar hidrodinamik yağlama teorisini anlamada etkili olmaktadır. Ulaşllan çözümler ve modellemeler yatak parametrelerini belirlemede önemli faydalar sağlamaktadır. Yapılan Reynolds Diferansiyel Yağlama Denkleminin çözümünde yatak tasarımı için genel olarak;

- Mil hız değeri küçüldükçe basınç değerinin küçüldüğü,

- Açıllk değeri büyüdükçe basınç değerinin küçüldüğü,

- Eksantrisite oranları arttıkça basıncın arttığı,

- Vizkosite değerleri arttıkça basıncın arttığı görülmüştür.

Eksantrisite oranları arttıkça (0.8 ve 0.9 için) Gao (2014) tarafından yapılan çalışma ile kıyaslandığında, MATLAB tarafından hesaplanan sonuçlar arasındaki fark da artmıștır. Tobias (2016) ve Mane ve Soni (2013) uzun yatak deney sonuçları karşılaştıııldığında ise pmax değeri hesaplanan değerden biraz uzaklaşmıștır. Elde edilen basınç dağılımları grafik sonuçlarından da açıkça görüleceği gibi, literatürdeki altı adet çalışma, hazırlanan Matlab programı ile uyumludur. Literatürde kullanılan geçerliliği ispatlanmış Comsol, Ansys-fluent ve Kissoft gibi bilgisayar programları ile karşılaştırması yapılan programın ulaştı̆̆ı yakınsak sonuçlar çalışmayı özgün kılmaktadır.

Yapılan sayısal örnek çözümünde ise mil hızının artması ile minimum yağ film kalınlı̆̆ının ve sürtünme katsayısının arttığı görülmektedir. Hızın artması ile seçilen örnek yatak parametrelerinin optimum yatak tasarım bölgesinden uzaklaștıkları görülmektedir.

\section{Çıkar Çatış̧ması (Conflict of Interest)}

Yazarlar tarafından herhangi bir çıkar çatışması beyan edilmemiştir. No conflict of interest was declared by the authors.

\section{Kaynaklar (References)}

Adatepe, H., Bıyıklığlu, A., 2009. Dinamik Yüklü Radyal Kaymalı Yataklarda Yağ Giriș Sıcaklığının Yatak Performansına Etkisi, Makine Teknolojileri Elektronik Dergisi Cilt: 6, No: 4, 2009 (1-10)

Adatepe, H., Cengil, M., Güneș, B., 2012. Statik Yük Altındaki Kaymalı Yataklarda Sürtünme Katsayısının Teorik ve Deneysel Olarak Belirlenmesi. Makine Teknolojileri Elektronik Dergisi Cilt: 9, No: 1, 2012(25-34)

Budynas, R., Nisbett,K., 2006. Shigley's Mechanical Engineering Design. McGraw-Hill Primis ISBN: 0-390-76487-6.

Durak, E., 2003. Borik Asitin Katkı Maddesi Olarak Yağlama Yağında Kullanılmasının Araștırılması, Balıkesir Üniversitesi Fen Bilimleri Enstitüsü Dergisi 5-1, 121-129.

Durak, E., 2019. Kaymalı yatak tasarımı kriterleri II, Erişim Tarihi: 23.05.2019. https://lubricant-world.com/kaymali-yataktasarimi-kriterleri-ii/

Frêne, J., Nicola, D., Degueurce, B., Berthe, D., Godet, M., 1997. Hydrodynamic lubrication bearings and thrust bearings. In Tribology series 33 (Ed. D. Dowson), 470 p. Elsevier, London, UK.

Frene, J., 1998. CFD Techniques in Hydrodynamic Lubrication, Ders Notları. Boğaziçi Üniversitesi, Makina Mühendisliği, İstanbul.

Gao, G., Yin, Z., Jiang, D., Zhang, X., 2014. Numerical analysis of Plain Journal Bearing under Hydrodynamic Lubrication by Water. Tribology International, 75, 31-38. doi:10.1016/j.triboint.2014.03.009

Grabon' W., Smykla J., 2012. Computer Program for Simulation of Pressure Distribution in the Hydrodynamic Radial Bearing. Artif Intell Driven Solut Bus Eng Prob, pp. 176-186 ISBN: 978-954-16-0060-3. 
Hashimoto, H., 1997. Surface Roughness Effects in High- Speed Hydrodynamic Journal Bearings, ASME Journal of Tribology, $119,4,776-780$.

Koç, E., 2008. Makina Elemanları Cilt 2., Adana Nobel Kitabevi, Adana.

Kurban, A.O., 1990. Eksenel Kaymalı Yataklarda Elastohidrodinamik Yağlama ve Elastik Deformasyona Uğrayabilen Kaymah Yatak Dizaynı. Erciyes Üniversitesi, Fen Bilimleri Enstitüsü, Doktora Tezi, 110s, Kayseri.

Liu, H., Xu, H., Ellison, P. J., Jin, Z., 2010. Application of Computational Fluid Dynamics and Fluid-Structure Interaction Method to the Lubrication Study of a Rotor-Bearing System. Tribology Letters, 38(3), 325-336. doi: 10.1007/s11249-010-9612-6.

Mane, R.M., Soni, S., 2013. Analysis of Hydrodynamic Plain Journal Bearing, Excerpt from the Proceedings of the 2013 COMSOL Conference in Bangalore.

Myung-Rae, C., Shin,H.J. ve Han,D.C., 2000. A Study On The Circumferential Groove Effects On The Minimum Oil Film Thickness In Engine Bearings Ksme International Journal, Vol. 14, No. 7, 737- 743.

Nuruzzaman, D. M., Khalil, M. K., Chowdhury, M. A., Rahaman, M. L., 2010. "Study on Pressure Distribution and Load Capacity of a Journal Bearing Using Finite Element Method and Analytical Method," International Journal of Mechanical \& Mechatronics Engineering IJMME-IJENS, vol. 10, no. 5.

Razavykia, A., Delprete, C., Baldissera, P., 2019. Numerical Study of Power Loss and Lubrication of Connecting Rod Big-End, Lubricants 7, 47; doi: 10.3390/lubricants7060047.

Salman,Ö, Durak, E., 2011. Çevre Dostu Bitkisel Yağ Esaslı Yağlama Yağları, YTÜ Sigma Mühendislik ve Fen Bilimleri Dergisi, Sigma 29,412-421.

Santos, E.N., Blanco, C.J.C., Mac^edo, E.N., Maneschy, C.E.A., Quaresma, J.N.N.,2012. Integral transform solutions for the analysis of hydrodynamic lubrication of journal bearings. Tribology International, $52 \mathrm{~s}, 161-169$.

Şimşek, M., 2014. Mikro Ark Oksidasyon İle Al203 Kaplanmış AA7075 Alaşımının Kuru Ve Yağlı Şartlarda Sürtünme Ve Așınma Davranışının İncelenmesi", Süleyman Demirel Üniversitesi, Fen Bilimleri Enstitüsü, Doktora Tezi, 232s, Isparta.

Singh, A., Verma, N., Chaurasia, A., Kumar, A., 2020. Effect of TiO2 Additive Volume Fraction in Lubricant Oil on the Performance of Hydrodynamic Journal Bearing. IOP Conf. Series:Materials Science and Engineering 802, doi:10.1088/1757899X/802/1/012005.

Soydan Y., Ulukan L., 2013. Temel Triboloji. Sürtünme- Aşınma Yağlama Bilimi ve Teknolojisi. Sakarya.

Sun, J., Changlin, G., 2004. Hydrodynamic Lubrication Analysis of Journal Bearing Considering Misalignment Caused by Shaft Deformation, Tribology International, Volume 37, Issue 10, Pages 841-848, https://doi.org/10.1016/j.triboint.2004.05.007

Syfris D., Chasalevris A., 2012. An Exact Analytical Solution of the Reynolds Equation for the Finite Journal Bearing. Tribology International. 55(1), pp. 46-58. doi:10.1016/j.triboint.2012.05.011

Temiz, V. 2014. Makina Elemanları 1 Triboloji Genel Bilgiler, Ders notları. Erişim tarihi: 15.05.2019. https://web.itu.edu.tr/temizv/Sunular/Triboloji.pdf.

Tobias H., 2016. Journal Bearing Design Tool: Time-dependent Analysis of Bearing Film Thickness, Power Loss and Load Response, Master of Science in Engineering Technology, Mechanical Engineering, Luleå University of Technology.

Wang Y., Yin Z., Jiang D., Gao G., Zhang X., 2016. Study of the lubrication performance of water-lubricated journal bearings with CFD and FSI method. Industrial Lubrication and Tribology, 68(3) pp. 341-348. doi: 10.1108/ILT-04-2015-0053.

Woloszynski, T., Podsiadlo P., Stachowiak, G.W., 2015. Efficient Solution to the Cavitation Problem in Hydrodynamic Lubrication, Tribology Letters volume 58, 18. 